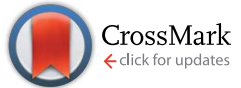

Cite this: Chem. Sci., 2016, 7, 745

\title{
Zwitterionic and biradicaloid heteroatomic cyclopentane derivatives containing different group 15 elements $\uparrow$
}

\begin{abstract}
Alexander Hinz, ${ }^{a}$ Axel Schulz*ab and Alexander Villinger ${ }^{a}$
The formal cyclopentane-1,3-diyl derivatives $\left[E^{1}(\mu-N T e r)_{2}\left(\left\{E^{2} C\right\}=N D m p\right)\right](T e r=2,6$-dimesityl-phenyl, Dmp $=2,6$-dimethylphenyl) were prepared by 1,1-insertion of CNDmp into the $N-E^{2}$ bond of $\left[E^{1}(\mu\right.$ $\left.N T e r)_{2} E^{2}\right]\left(E^{1}=N, P ; E^{2}=P\right.$, As). The insertion does not occur for $E^{1}=E^{2}=A s$ or $E^{2}=S b$. Dependent on the choice of formal radical centres $E$, either a biradicaloid or a zwitterion was obtained. The biradicaloid features a $\mathrm{P}$ and an As radical center and its biradical character was established by computations as well as characteristic reactivity with respect to the formation of a housane derivative and the activation of molecules bearing multiple bonds, which was demonstrated using the example of $\mathrm{PC}^{t} \mathrm{Bu}$. In contrast, the formally N,As- and N,P-centered biradicaloids are better regarded as zwitterionic species in accord with computations and diminished reactivity, as neither housane formation nor activation of multiple bonds could be observed.
\end{abstract}

Received 17th September 2015 Accepted 26th October 2015

DOI: $10.1039 / \mathrm{c} 5 \mathrm{sc} 03515 \mathrm{e}$

www.rsc.org/chemicalscience

$\left[\mathrm{E}^{1}(\mu-\mathrm{NTer})_{2} \mathrm{E}^{2}\right]\left(\mathrm{E}^{1}=\mathrm{N}\right.$ with $\mathrm{E}^{2}=\mathrm{P}, \mathrm{As}, \mathrm{Sb} ; \mathbf{1} \mathbf{E}^{\mathbf{1}} \mathbf{E}^{2}$ in Scheme 2). ${ }^{32,33}$ The reactivity of singlet biradicaloids was mainly studied using the examples of diboradiphosphonio-cyclobutanediyls $\left[{ }^{\mathrm{i}} \mathrm{Pr}_{2} \mathrm{P}\left(\mu-\mathrm{B}^{t} \mathrm{Bu}\right)\right]_{2},{ }^{35,36}$ diphosphacyclobutane-diyls $\left[\mathrm{ClC}\left(\mu \text {-PMes }{ }^{*}\right)\right]_{2}$ (Mes ${ }^{*}=2,4,6$-tri- ${ }^{\text {tert }}$ butylphenyl $),{ }^{37,38}$ diphosphadiazanediyls $[\mathrm{P}(\mu-$ $\mathrm{NTer})]_{2} \quad\left(\right.$ Ter $=$ 2,6-bis(2,4,6-trimethylphenyl)phenyl), ${ }^{39,40}$ and digermynes $\quad \mathrm{R}_{2} \mathrm{Ge}_{2} \quad(\mathrm{R}=2,6$-bis(2,6-diisopropylphenyl) phenyl). ${ }^{31,41-43}$ For the triazenide-derived species $\left[\mathrm{E}^{2}(\mu-\mathrm{NTer})_{2} \mathrm{~N}\right]$, only diminished reactivity was observed, hence these are better regarded as zwitterionic compounds than as biradicaloids in agreement with computational studies. In the case of $[\mathrm{Sb}(\mu-$ NTer $)_{2} \mathrm{P}$, the biradicaloid was found to be a transient intermediate, whose existence could be proven by trapping experiments. ${ }^{34}$

A viable access to a stable singlet derivative of formal heteroatomic cyclopentane-1,3-diyls was found in the 1,1-insertion of carbon monoxide, $\mathrm{C} \equiv \mathrm{O}$, into cyclodiphospha diazanediyl, $[\mathrm{P}(\mu \text {-NTer })]_{2}$ (1PP), which afforded species $\mathbf{E}$ (Scheme 2). ${ }^{4 \mathbf{4}}$ Subsequent systematic investigations targeted the activation of isonitriles, $\mathrm{C} \equiv \mathrm{N}-\mathrm{R}\left(\mathrm{R}={ }^{t} \mathrm{Bu}, \mathrm{Dmp}, \mathrm{N}\left(\mathrm{SiMe}_{3}\right)_{2}\right.$, Ter; Ter $=2,6-$ dimesityl-phenyl, Dmp = 2,6-dimethylphenyl), with diphosphadiazanediyl 1PP. By variation of the organic substituent, protocol was devised by our group, enabling the synthesis of the formal group-15-substituted cyclobutanediyls $\left[\operatorname{As}(\mu-\mathrm{NTer})_{2} \mathrm{P}\right]$ and

${ }^{a}$ Institut für Chemie, Universität Rostock, Albert-Einstein-Str. 3a, 18059 Rostock, Germany.E-mail: axel.schulz@uni-rostock.de

${ }^{b}$ Abteilung Materialdesign, Leibniz-Institut für Katalyse e.V. an der Universität Rostock, Albert-Einstein-Str. 29a, 18059 Rostock, Germany

$\dagger$ Electronic supplementary information (ESI) available: Additional experimental details, full characterization of all compounds and computational details. CCDC 1421413-1421416. For ESI and crystallographic data in CIF or other electronic format see DOI: $10.1039 / \mathrm{c} 5 \mathrm{sc} 03515 \mathrm{e}$

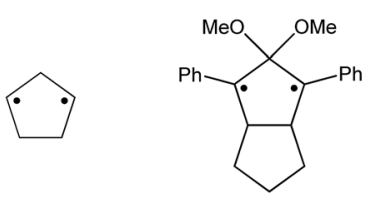

A
B

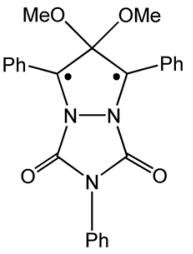

C

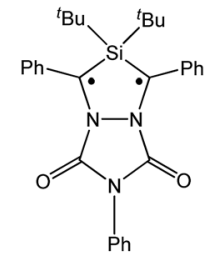

D

Scheme 1 Selected known cyclopentane-1,3-diyl derivatives (A-D). 


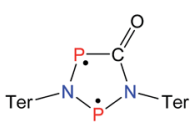

$\mathbf{E}$

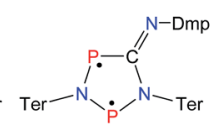

$\mathbf{F}$

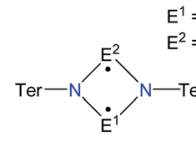

$1 E^{1} E^{2}$
$=\mathrm{N}, \mathrm{P}, \mathrm{As}$

$=\mathrm{P}, \mathrm{As}, \mathrm{Sb} \quad \mathrm{N}-\mathrm{Dmp}$

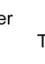

Ter $-{ }^{N}-\dot{E}^{1}-N-T e r$

$2 E^{1} E^{2}$
Scheme 2 Stable cyclopentane-1,3-diyl derivatives (E and F), group15-substituted cyclobutanediyls (1) and the targeted cyclopentane1,3-diyls (2).

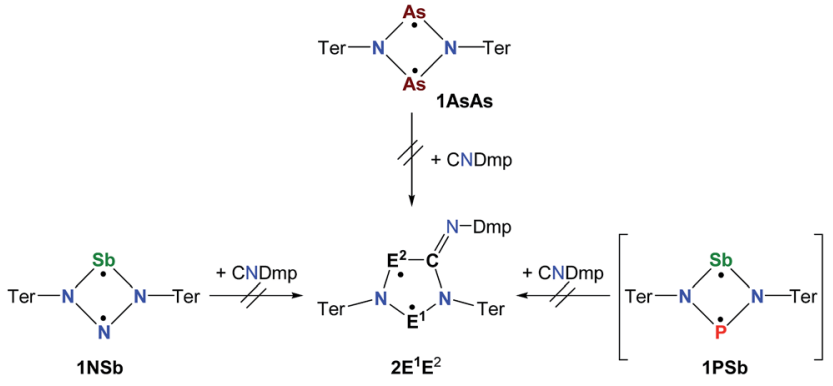

Scheme 3 Not accessible cyclopentane-1,3-diyl derivatives (2AsAs, 2NSb, 2PSb).

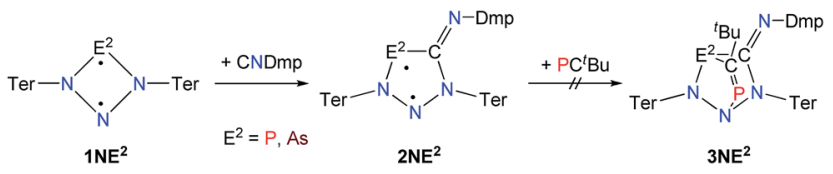

Scheme 4 Formation of 2NP and 2NAs.

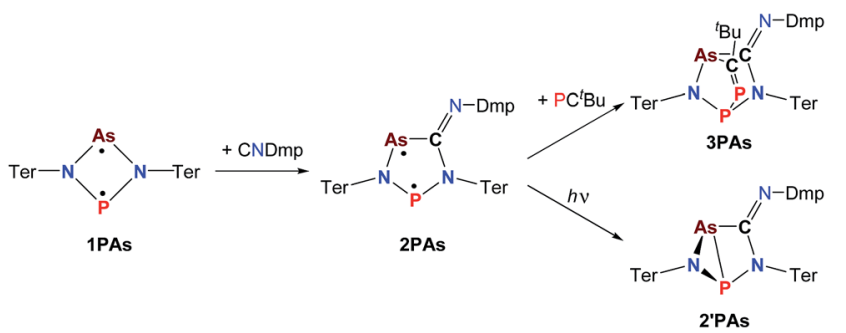

Scheme 5 Synthesis and reactivity of P,As-centered cyclopentane1,3-diyl derivative 2PAs, housane formation on irradiation (365 nm) and addition reaction to 3PAs.

steric and electronic properties of the isonitrile could be varied. These could be adjusted to cleanly afford the cyclopentane-1,3diyl derivative, when 2,6-dimethylphenyl-isonitrile was utilized (species F, Scheme 2). ${ }^{45}$ In this contribution, we report on the formation of cyclopentane-1,3-diyls bearing different group 15 radical centres $\left(\mathbf{2 E}^{\mathbf{1}} \mathbf{E}^{\mathbf{2}}\right)$ by reaction of the available group 15 cyclobutanediyl derivatives $\left(\mathbf{1 E}^{\mathbf{1}} \mathbf{E}^{\mathbf{2}}\right)$ with a selected isonitrile, $\mathrm{C} \equiv \mathrm{N}-\mathrm{Dmp}$ (Schemes 3-5).

\section{Results and discussion}

\section{Synthesis}

Cyclobutanediyl derivatives $\mathbf{1 E}^{\mathbf{1}} \mathbf{E}^{\mathbf{2}}$ are strongly coloured compounds. ${ }^{32,33,46}$ Thus, the reactions can often easily be followed visually, apart from reaction monitoring by NMR spectroscopy. While the diphosphadiazanediyl 1PP readily reacted with 2,6-dimethylphenyl-isonitrile to give $2 \mathbf{P P},{ }^{45}$ no such transformation was observed when the heavier homologue diarsadiazanediyl 1AsAs was utilized (Scheme 3). Also, neither the antimony-containing species, stable $\mathbf{1 N S b}$, nor in situ generated 1PSb, reacted with CNDmp at all.

On the contrary, the ring expansion reaction of the triazenide-derived cyclobutanediyl derivatives 1NP and 1NAs proceeded smoothly (Scheme 4) when a solution of CNDmp in benzene was added slowly at ambient temperature to a solution of 1NP and 1NAs, respectively, in benzene. Since the starting material 1NP could not be isolated due to the recurring formation of the triazenide $\operatorname{Ter}_{2} \mathrm{~N}_{3} \mathrm{H}$ as an impurity, ${ }^{33}$ the insertion of the isonitrile and subsequently, the attempted conversion with $\mathrm{PC}^{t} \mathrm{Bu}$, was investigated by means of spectroscopy. The ${ }^{31} \mathrm{P}$ NMR spectrum of $1 \mathrm{NP}$ displays a singlet resonance at $+342.4 \mathrm{ppm}$, that shifts to $+167.3 \mathrm{ppm}$ upon addition of the isonitrile, indicating the formation of 2NP in good agreement with 1,2,3,4-triazaphospholes prepared by Müller et al. and Jones et al. utilizing "click reaction" of azides with phosphaalkynes (e.g. $\left.\mathrm{C}_{5} \mathrm{NH}_{4}-\mathrm{N}_{3} \mathrm{PC}-{ }^{t} \mathrm{Bu} 167.5 \mathrm{ppm}\right) .{ }^{47-50}$ It should be noted that various attempts of crystallization only afforded the triazenide $\mathrm{Ter}_{2} \mathrm{~N}_{3} \mathrm{H}$ and the product $2 \mathrm{NP}$ could not be isolated. Upon insertion of the isonitrile, the colour of the solution changed from yellow (1NP) to red (2NP: $\lambda_{\max }=490$, calc. 476 $\mathrm{nm}) .^{51,52}$ The attempted addition of $\mathrm{PC}^{t} \mathrm{Bu}$ did not alter any of these characteristics, indicating that no reaction with $2 \mathbf{N P}$ occurred in accord with a rather small biradical character (see below).

The reaction of 1NAs with CNDmp similarly resulted in a change of colour from initially yellow $\left(\lambda_{\max }=379 \mathrm{~nm}\right)$ to red, indicating the presence of 2 NAs $\left(\lambda_{\max }=523\right.$, calc. $\left.518 \mathrm{~nm}\right)$. Similar to 2NP, 2NAs features a $\nu(\mathrm{C}=\mathrm{N})$ vibration at 1612 in the Raman and at $1610 \mathrm{~cm}^{-1}$ in the IR spectrum which is significantly different from the $\nu(\mathrm{C} \equiv \mathrm{N})$ vibration of pure CNDmp exhibiting a $\mathrm{CN}$ triple bond $\left(2123 \mathrm{~cm}^{-1}\right)$. Crystals suitable for single X-ray studies were obtained after concentration at $4{ }^{\circ} \mathrm{C}$ in good yields (83\%). Red needle-shaped crystals of 2NAs decompose above $141^{\circ} \mathrm{C}$ and are moisture and air sensitive. Like 2NP, 2NAs does not react with $\mathrm{PC}^{t} \mathrm{Bu}$ also displaying diminished biradical character. The molecular structure of 2NAs (Fig. 1) features a planar five-membered $\mathrm{N}_{3}$ CAs heterocycle. The As-N bond of 1.875(3) $\AA$ is considerably longer than in the known tetrazarsole galliumtrichloride adduct $\mathrm{Mes}^{*} \mathrm{~N}_{4} \mathrm{As} \cdot \mathrm{GaCl}_{3}$ (1.784(2), 1.805(2) ̊; $c f . \Sigma r_{\text {cov }}($ As-N) $=1.91 ~ \AA)$ indicating single bond character. ${ }^{53}$ The same holds true for the As-C bond with $1.902(4) \AA\left(\sum r_{\text {cov }}(\right.$ As-C $\left.)=1.97 \AA\right)$. The $\mathrm{N}-\mathrm{N}$ distances in 2NAs of 1.316(4) and 1.349(4) A are between the sum of covalent radii for a double and a single bond $(1.20,1.42 \AA)$, indicating delocalized double bond character, while the C49-N3 bond length (1.428(5) $\AA)$ corresponds to a single bond $\left(\Sigma r_{\text {cov }}(\mathrm{C}-\mathrm{N})=1.46 \AA\right)$ contrary to the exocyclic C49-N4 bond (1.293(5) $\mathrm{A})$ which is in the typical range of a $\mathrm{C}=\mathrm{N}$ double bond. ${ }^{54}$

In a next series of experiments we treated a solution of 1PAs in benzene with CNDmp. Within 10 minutes the insertion of CNDmp into the dark purple 1PAs $\left(\lambda_{\max }=550 \mathrm{~nm}\right)^{32}$ led in good 


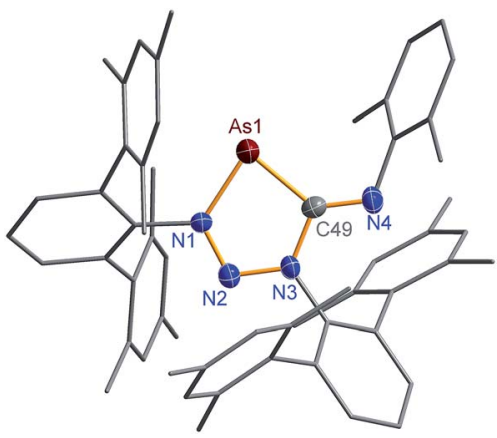

Fig. 1 Molecular structure of 2NAs. Thermal ellipsoids are drawn at $50 \%$ probability $(173 \mathrm{~K})$. Selected bond lengths [Å] and angles [ $\left.{ }^{\circ}\right]$ : $2 \mathrm{NAs}$ : As1-N1 1.875(3), As1-C49 1.902(4), N1-N2 1.316(4), N2-N3 1.349(4), N3-C49 1.428(5), N4-C49 1.293(5); N1-As1-C49 82.71(16), N2-N1As1 119.4(2), N1-N2-N3 109.8(3), N2-N3-C49 119.4(3).

yields (68\%) to a singlet biradicaloid cyclopentanediyl derivative, 2PAs, which is of green colour $\left(\lambda_{\max }=431,684\right.$, calc. 454 , $674 \mathrm{~nm}$, Scheme 5). Interestingly, at the beginning of the reaction the reaction mixture appeared dark grey due to the presence of both the starting material and the reaction product. Astonishingly, the ${ }^{31} \mathrm{P}$ NMR shift merely changed from 268.8 to $269.0 \mathrm{ppm}$. However, as discussed before, upon incorporation of the isonitrile into the four-membered biradicaloid, the $\nu(\mathrm{CN})$ vibration is dramatically shifted from 2123 to $1633 \mathrm{~cm}^{-1}$, as expected for the transition from a $\mathrm{C}-\mathrm{N}$ triple to double bond. Crystals of 2PAs decompose above $122^{\circ} \mathrm{C}$.

The connectivity is furthermore corroborated by the ${ }^{13} \mathrm{C}$ NMR data, in which the former isonitrile carbon atom gives rise to a resonance at $184.98 \mathrm{ppm}$, which appears as doublet with a small $J_{\mathrm{CP}}=9.9 \mathrm{~Hz}$, indicating a ${ }^{2} J$ coupling. X-ray diffraction experiments on single crystals of 2PAs revealed a secondary irradiation-induced isomerization to the housane isomer $\mathbf{2}^{\prime} \mathbf{P A s}$ (Scheme 5, Fig. 2, see below), as it was observed for cyclopentanediyl derivatives such as $\mathbf{2 P P}$ indicating substantial biradical character. ${ }^{44,45}$ However contrary to 2PP, for 2PAs this isomerization did not cause the crystals to completely decompose. Two data sets were collected from a single crystal: the first data set without irradiation prior to measurement and the second after 12 hours of X-ray irradiation on the diffractometer. In both cases, the structural model features disordered $\mathrm{P}$ and As atoms. While in the first data set, the planar five-membered species is dominant ( $86 \%$ occupation, Fig. 2 top), in the second data set, which was collected after 12 hours of X-ray irradiation, 95\% occupation are found for the housane species (Fig. 2 top). In solution, all attempts to generate $\mathbf{2}^{\prime} \mathbf{P A s}$ by UV irradiation of 2PAs led to decomposition, thus no NMR data for 2 'PAs could be obtained.

The biradical character of 2PAs invokes high reactivity, which could be demonstrated in the activation of molecules such as phosphaalkynes, $\mathrm{PC}^{t} \mathrm{Bu}$, bearing a $\mathrm{P} \equiv \mathrm{C}$ triple bond. The initially green solution of 2PAs in benzene quickly turned yellow upon addition of the phosphaalkyne and formation of 3PAs was observed in good yields (78\%, Scheme 5 , Fig. 3$)$. The ${ }^{31} \mathrm{P}$ NMR spectrum exhibited an AB spin system $(331.8,156.8$
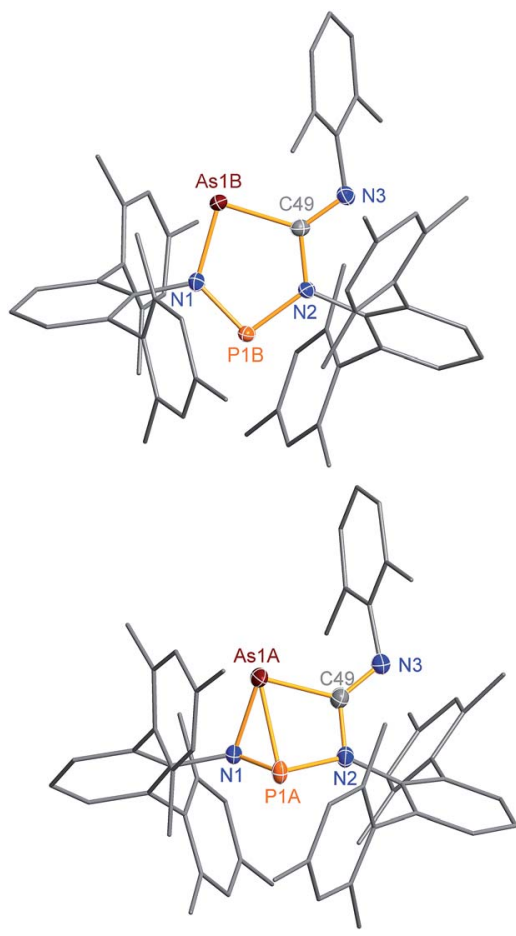

Fig. 2 Molecular structure of 2PAs (top) and 2'PAs (bottom). Thermal ellipsoids are drawn at $50 \%$ probability $(123 \mathrm{~K})$. Selected bond lengths $[\AA ̊]$ and angles $\left[{ }^{\circ}\right]$ : 2PAs: As1B-N1 1.874(2), As1B-C49 1.937(2), P1B-N1 1.636(2), P1B-N2 1.691(2), As1B-P1B 3.049(2), P1B-N1-As1B 120.5(1); 2'PAs: As1A-P1A 2.2920(7), As1A-C49 2.011(2), As1A-N1 1.970(2), $\mathrm{P} 1 \mathrm{~A}-\mathrm{N} 1$ 1.692(2), P1A-N2 1.801(2), N1-P1A-N2 95.12(7), P1A-N1As1A 77.10(6).

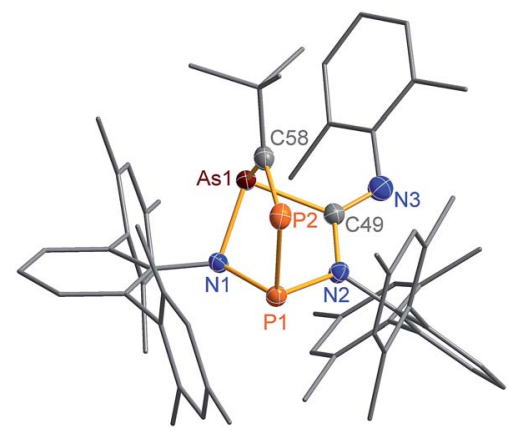

Fig. 3 Molecular structure of 3PAs. Thermal ellipsoids are drawn at $50 \%$ probability $(173 \mathrm{~K})$. Selected bond lengths $[\AA \AA]$ and angles $\left[{ }^{\circ}\right]$ : 3PAs: As1-N1 1.895(2), As1-C58 1.996(2), As1-C49 2.007(2), P1-N1 $1.7378(18), \mathrm{P} 1-\mathrm{N} 2$ 1.756(2), P1-P2 2.2822(8), P2-C58 1.673(2), N3C49 1.270(3), N1-As1-C58 93.47(9), C58-P2-P1 96.42(8), P1-P2C58-As1-2.50(13).

$\mathrm{ppm}$ ), indicating that exclusively one isomer was formed. The strong $J_{\mathrm{PP}}$ coupling of $260 \mathrm{~Hz}$ is characteristic for a ${ }^{1} J_{\mathrm{PP}}$ coupling constant. Single crystal X-ray structure elucidation unequivocally revealed the exclusive formation of one isomer (P-P and CAs bonded species, Fig. 3) therefore featuring complete regioselectivity. This regioselectivity is most probably caused by steric hindrance, as the formation of the putative C-P and P-As bonded isomer would considerably distort the "pocket" formed 
by the two terphenyls, which is already opened to one side due to insertion of the isonitrile (difference between both isomers: $\Delta E=48 \mathrm{~kJ} \mathrm{~mol}^{-1}$ ). It is interesting to note that for the cyclobutanediyl derivative $\left[\operatorname{As}(\mu-\mathrm{NTer})_{2} \mathrm{P}\right]$, the regioselectivity was opposite and only the $\mathrm{C}-\mathrm{P}$ and $\mathrm{P}-\mathrm{As}$ bonded isomer was observed due to thermodynamic preference of a $\mathrm{C}-\mathrm{P}$ over $\mathrm{C}-\mathrm{As}$ bond. $^{32}$

Single crystals of 2PAs/2'PAs and 3PAs suitable for structure analysis were obtained from benzene solutions. The most prominent structural feature of 2PAs represents the almost planar five-membered heterocycle with rather short $\mathrm{P}-\mathrm{N}$ bond lengths (P1B-N1 1.636(2), P1B-N2 1.691(2) $\AA$ ) in the range of PN double bonds $\left(\Sigma r_{\text {cov }}(\mathrm{P}=\mathrm{N})=1.62 \AA\right)$, while the As-N (As1B-N1

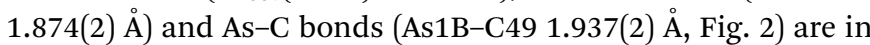
the range of single bonds (see also 2NAs, Fig. 1)..$^{53,55,56}$

The structure changes dramatically upon irradiation and formation of the housane $\mathbf{2}^{\prime} \mathbf{P A s}$. The transannular P-As distance is shortened from 3.049(2) to 2.2920(7) A clearly indicating the presence of a transannular $\mathrm{P}-\mathrm{As}$ single bond $\left(\Sigma r_{\text {cov }}(\mathrm{P}-\right.$ As) $=2.32 \AA$ ). Additionally, the P-N-As angle strongly decreases from $120.5(1)$ to $77.10(6)^{\circ}$. The three-membered As-N-P ring is almost perpendicular condensed to the four-membered As-P$\mathrm{N}-\mathrm{C}$ ring. These experimental structural parameters are in good agreement with those of DFT computations (see below and ESI $\dagger$ ).

The phosphaalkyne addition product 3PAs shows a puckered five-membered ring with a transannular $\mathrm{P}$-As distance of 2.918(2) Å. The P-C bridging bond length amounts to 1.673(2) in accord with a $\mathrm{P}=\mathrm{C}$ double bond.

\section{Computations - bonding and biradical character}

To shed some light into the bonding and biradical character, MO (Fig. 4), NBO (Scheme 6) and CASSCF computations have been carried out. MO and NBO computations show formal $6 \pi$ electronic $\mathbf{2} \mathbf{E}^{\mathbf{1}} \mathbf{E}^{\mathbf{2}}$ five-membered heterocycles (Table 1). A common electronic feature of the heterocycles 2NP, 2NAs, and 2PAs is the weak aromaticity as indicated by NICS values (Table 1). ${ }^{57}$ The frontier orbitals feature a p-type transannular antibonding $\pi$-HOMO and transannular bonding $\pi *$-LUMO between the radical centres, in accord with other group 15 singlet biradicaloids (Fig. 4).

To investigate the biradicaloid character of $2 \mathbf{E}^{\mathbf{1}} \mathbf{E}^{\mathbf{2}}$, the singlet-triplet energy gap $\left(\Delta E_{\mathrm{S}-\mathrm{T}}\right)$ was computed for $2 \mathbf{E}^{\mathbf{1}} \mathbf{E}^{\mathbf{2}}$ and CASSCF $(6,6)$ computations were carried out (CASSCF = complete active space self-consistent field). Experimentally, biradicaloids $2 \mathbf{E}^{\mathbf{1}} \mathbf{E}^{\mathbf{2}}$ show no EPR signal and ${ }^{1} \mathrm{H},{ }^{13} \mathrm{C}$, and ${ }^{31} \mathrm{P}$ NMR signals. All $2 \mathbf{E}^{\mathbf{1}} \mathbf{E}^{\mathbf{2}}$ compounds have a singlet ground state in accord with rather large $\Delta E_{\mathrm{S}-\mathrm{T}}$ values (Table 1) significantly decreasing the heavier the group 15 elements $\mathrm{E}^{1}$ and $\mathrm{E}^{2}$. CASSCF $(6,6)$ computations confirmed the biradicaloid nature of $2 \mathbf{E}^{\mathbf{1}} \mathbf{E}^{\mathbf{2}}$. The dominant contributions to the CI wave function arise from the HOMO/LUMO exchange. The biradicaloid character can be estimated by using the formula: $\beta=2 c_{2}{ }^{2} /\left(c_{1}{ }^{2}+\right.$ $\left.c_{2}{ }^{2}\right) .{ }^{58}$ Hence, upon insertion of the isonitrile into the fourmembered ring of $\mathbf{1}$ the biradical character is preserved compared to the starting material $\mathbf{1 E}^{\mathbf{1}} \mathbf{E}^{\mathbf{2}}$. Therefore, as illustrated in Scheme 6 and Table 1, the zwitterionic character increases (biradical character decrease) along $\mathrm{E}^{1}=$ As $<\mathrm{P}<\mathrm{N}$ and $\mathrm{E}^{2}=\mathrm{Sb}<\mathrm{As}<\mathrm{P}$. For example, a biradical character $\beta$ of only $13 \%$ was computed for 2 NP and $11 \%$ for 2 NAs, respectively (CASSCF(6,6), coefficients of main contributions $0.946,-0.250$ for 1NP and 0.956, -0.229 for 1NAs). ${ }^{58}$ However, 2PAs features substantial biradical character of $\beta=24 \%\left(\operatorname{CASSCF}(6,6), c_{1}=\right.$ 0.916 and $\left.c_{2}=-0.339\right)$, in agreement with the experimental fact that this species is capable of activating molecules containing triple bonds (vide supra) contrary to 2NP or 2NAs. Moreover, the larger zwitterionic character of 2NAs compared to 2PAs is also
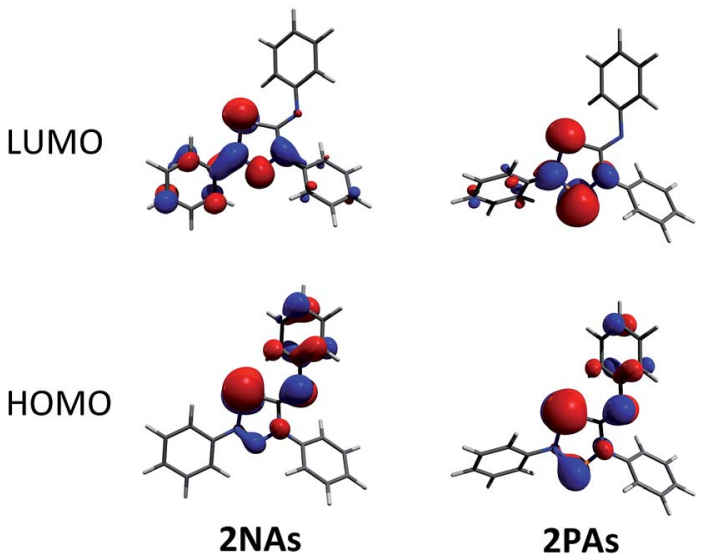

Fig. 4 Frontier orbitals of 2NAs (left) and 2PAs (right). For the orbital representations phenyl-substituted model compounds are used for clarity.

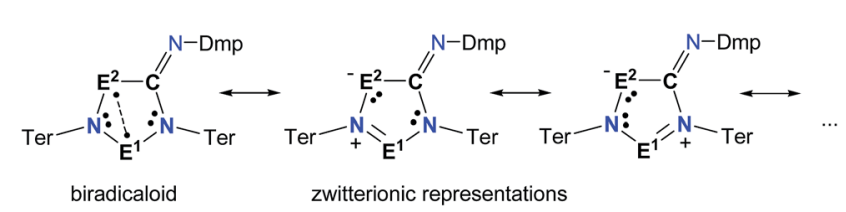

Scheme 6 Selected Lewis representations according to NBO analysis.

Table 1 Computational data for the cyclopentanediyls $2 E^{1} E^{2}$ with Ter substituents

\begin{tabular}{|c|c|c|c|c|c|c|}
\hline & $2 \mathrm{NP}$ & 2NAs & $2 \mathrm{NSb}^{a}$ & 2 PAs & $2 \mathrm{PSb}^{a}$ & $2 \mathrm{AsAs}^{a}$ \\
\hline$\lambda_{\max }$ calc. & 476 & 518 & 542 & 674 & 715 & 750 \\
\hline$\Delta E_{\text {form }}{ }^{b}$ & -148.0 & -114.6 & -55.6 & -94.8 & -51.4 & -91.2 \\
\hline $\mathrm{S}-\mathrm{T}$ gap $^{b}$ & -148.9 & -132.7 & -118.8 & -75.4 & -72.7 & -44.4 \\
\hline$\beta^{c}$ & $13 \%$ & $11 \%$ & $4 \%$ & $24 \%$ & $7 \%$ & $38 \%$ \\
\hline$c_{1}$ & 0.946 & 0.956 & 0.961 & 0.916 & 0.982 & 0.889 \\
\hline$c_{2}$ & -0.250 & -0.229 & -0.132 & -0.339 & -0.185 & -0.433 \\
\hline $\mathrm{BO}(\mathrm{E}-\mathrm{E})^{f}$ & 0.313 & 0.288 & 0.262 & 0.389 & 0.343 & 0.434 \\
\hline$\pi{\text { e } \operatorname{cpd}^{d}}^{d}$ & 6.51 & 6.51 & 6.55 & 6.49 & 6.53 & 6.50 \\
\hline $\operatorname{NICS}(0)^{e}$ & -8.32 & -7.45 & -6.40 & -5.62 & -4.84 & -4.66 \\
\hline $\operatorname{NICS}(1)^{e}$ & -6.65 & -6.10 & -5.51 & -3.24 & -3.18 & -2.90 \\
\hline
\end{tabular}

${ }^{a}$ Species not isolated. ${ }^{b}$ Calculated in $\left[\mathrm{kJ} \mathrm{mol}^{-1}\right]: \Delta E_{\text {form }}=E(\mathbf{2})-[E(\mathbf{1})+$ $E(\mathrm{CNDmp})] .{ }^{c} \beta=2 c_{2}{ }^{2} /\left(c_{1}{ }^{2}+c_{2}{ }^{2}\right)$, the two main contributions according to $\operatorname{CASSCF}(6,6)$ computations were used. ${ }^{d} \pi$ electrons in $\mathrm{cpd}=$ cyclopentanediyl, occupation of $\mathrm{p}_{z}$ orbitals in the five-membered heterocycle according to NBO analysis. ${ }^{e}$ In ppm. ${ }^{f}$ Wiberg bond index. 
manifested by the HOMO of 2NAs featuring very large coefficients at As and very small ones at $\mathrm{N}$, while for 2PAs the contributions are distributed almost evenly.

The computational data show a correlation between biradical character $\beta$ and Wiberg bond index (WBI) between the two radical centers (Table 1$)$. The $\operatorname{WBI}\left(\mathrm{E}^{1}-\mathrm{E}^{2}\right)$ of all considered species $2 \mathbf{E}^{\mathbf{1}} \mathbf{E}^{2}$ ranges from 0.262 to 0.434 , which originates from partial occupation of the transannularly bonding LUMO. This reflects strong antiferromagnetic coupling between the radical centers $\mathrm{E}^{1}$ and $\mathrm{E}^{2}$. NICS values (between -2.9 and -8.3 , Table 1 , cf. benzene $-\mathbf{1 1 . 5} \mathrm{ppm}$, azulene -21.5 [5 ring] and -8.3 [7 ring] $\mathrm{ppm}$ ) decrease when heavier elements are incorporated in the five-membered ring, indicating less stabilization by electron delocalization within the heterocycle, which is due to diminished orbital overlap between $\mathrm{E}$ and the adjacent $\mathrm{N}$ or $\mathrm{C}$ atoms.

In analogy to the activation of $\mathrm{CO}$ with 1PP and the reaction of 1PP with different isonitriles, we suggest a mechanism involving the formation of a [1.1.1]bicyclic intermediate, which subsequently rearranges to give the cyclopentanediyl derivative (Scheme 7). ${ }^{\mathbf{4 4 4 5}}$ The formation of the [1.1.1]bicyclic species is endothermic for all species $2 \mathbf{E}^{\mathbf{1}} \mathbf{E}^{2}$ with $\mathrm{E}^{1}$ or $\mathrm{E}^{2}$ being $\mathrm{N}$, increasing in the order As $(62.8)<\mathrm{P}(82.0)<\mathrm{Sb}\left(126.8 \mathrm{~kJ} \mathrm{~mol}^{-1}\right)$ for $\mathrm{E}$. For the heavier homologues with $\mathrm{E}^{1}$ being $\mathrm{P}$, it is exothermic and the reaction energy increases in the same order: $\mathrm{E}^{2}=\mathrm{As}(-68.8)<\mathrm{P}(-49.9)<\mathrm{Sb}\left(-28.9 \mathrm{~kJ} \mathrm{~mol}^{-1}\right)$. The second reaction step, the rearrangement from the [1.1.1] bicycle to the planar five-membered ring, is exothermic in every case. In this case, there is a tendency of the reaction becoming less exothermic as the pnictogen $\mathrm{E}^{2}$ becomes heavier $\left(\Delta_{\mathrm{R}} \mathrm{E}: \mathrm{N}>\mathrm{P}>\right.$ As > Sb; e.g. 2PAs - 66.5, 2PAs - 30.9, 2PSb - 7.0; Table S3 $\dagger$ ), with the exception of $\mathrm{E}^{1}=\mathrm{N}$ and $\mathrm{E}^{2}=\mathrm{Sb}$, which is slightly more exothermic than for $\mathrm{E}^{2}=$ As. In all combinations of $\mathrm{E}^{1}$ and $\mathrm{E}^{2}$ being $\mathrm{N}, \mathrm{P}, \mathrm{As}$, or $\mathrm{Sb}$, the overall insertion reaction is exothermic (e.g. 2NP -148.0, 2NAs -114.6, 2NSb-55.6 kJ mol ${ }^{-1}$; Tables S2 and $\mathrm{S} 3 \dagger)$. Interestingly, all cyclopentanediyl derivatives $\mathbf{1}$ in which $\mathrm{E}^{1}$ is heavier than $\mathrm{E}^{2}$ are thermodynamically more stable than the observed species, in which $\mathrm{E}^{2}$ is heavier than $\mathrm{E}^{1}$. This means, that the observed products are formed owing to kinetic reaction control. This is plausible, since the heavier $\mathrm{E}-\mathrm{N}$ bonds are weaker and hence more readily activated. This can be corroborated with computed transition states for the rearrangement from [1.1.1] bicycle to planar five-membered ring for the example of a phenyl-substituted model compound of 2PAs, in which the insertion into the $\mathrm{N}-\mathrm{As}$ bond requires $16 \mathrm{~kJ} \mathrm{~mol}^{-1}$ less activation energy than into the N-P bond.

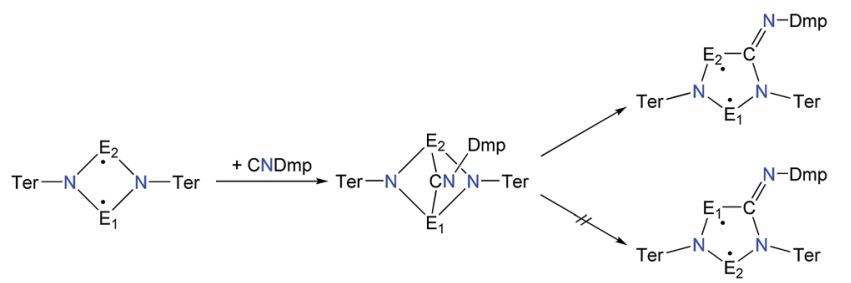

Scheme 7 Proposed reaction mechanism for isonitrile activation with $1 \mathrm{E}^{1} \mathrm{E}^{2}$ ( $\mathrm{E}^{1}$ is lighter than $\mathrm{E}^{2}$ ).

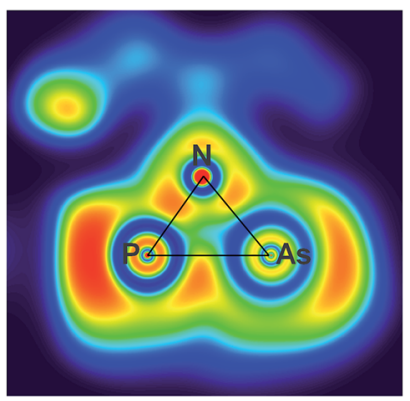

Fig. 5 ELF representation of $2 \mathrm{P}^{\prime} \mathrm{As}$ utilizing a phenyl substituted model compound for clarity. A section of the N-P-As plane is shown. The maximum is located aside the axis between As (left) and $P$ (right).

Finally, we want to address the issue of housane formation. Computational studies indicate, that 2PAs is more favorable than the housane isomer $2^{\prime} \mathbf{P A s}$ by $94 \mathrm{~kJ} \mathrm{~mol}^{-1}$. The computed activation barrier for the formation of the P-As bond amounts to $167 \mathrm{~kJ} \mathrm{~mol}^{-1}$ and breaking the bond $73 \mathrm{~kJ} \mathrm{~mol}^{-1}$. These values are higher than computed for the previously investigated housanes ( $42 \mathrm{~kJ} \mathrm{~mol}^{-1}$ difference in energy, activation barrier of $\left.83 \mathrm{~kJ} \mathrm{~mol}^{-1}\right) .^{45}$ This provides an explanation for the slower decomposition in the X-ray beam of the diffractometer, which allowed the structure determination of 2PAs as well as 2'PAs. However, upon UV irradiation, decomposition occurred, preventing the isolation of the housane species $2^{\prime}$ PAs.

The electronic situation of both isomers clearly differs, as the housane features a bent bond between the former radical centres, while in the biradicaloid there is no direct interaction between $\mathrm{P}$ and As. This is apparent from the maximum in the ELF (electron localization function) aside the P-As axis of $2^{\prime} \mathbf{P A s}$, which also features a localized double bond (Fig. 5).

\section{Conclusions}

In summary, the ring expansion reaction of cyclobutanediyls with isonitriles enabled the synthesis of three new group 15 derivatives of cyclopentane-1,3-diyl featuring N/P, N/As, or P/As atoms as radical centres within the five-membered heterocycle. However, there are limitations to this insertion reaction, and the preparation of cyclopentane-1,3-diyls bearing N/Sb, As/As, or $\mathrm{P} / \mathrm{Sb}$ radical centres remains a challenge. Two reasons can be accountable for this: (i) in the zwitterionic border case, due to strong polarization the valence electron density distributed far from equally between the formal radical centres, so the biradical reactivity is diminished, and (ii) by incorporating heavier elements in the heterocycle (e.g. within the homologous series 2NP, 2NAs, 2NSb), the distance between the radical centres is large and hence the orbital overlap is small, thereby reducing the stability of the heavier cyclopentane-1,3-diyl species. This is reflected in the decreasing relative stability of the singlet ground state compared to the lowest lying triplet state.

The new cyclopentane-1,3-diyl derivatives containing an $\mathrm{N}_{3}$ moiety $\left(\mathrm{E}^{1}=\mathrm{N}\right)$ have strongly polarized $\mathrm{N}-\mathrm{E}^{2}$ bonds, a rather small biradical character and therefore are better referred to as zwitterions, which is also manifested by their inability to 
activate molecules bearing multiple bonds. In contrast, the P/As centered biradicaloid 2PAs exhibits a considerable biradical character, higher reactivity and can be isomerized to the shortbond species 2'PAs or be utilized in small molecule activation.

\section{Acknowledgements}

The authors thank the DFG (SCHU 1170/11-1) for financial support. M.Sc. Jonas Bresien is gratefully acknowledged for setting up and maintaining Gaussian and NBO software on the cluster computer. A. H. thanks the GDCh for financial support.

\section{Notes and references}

1 M. J. S. Dewar, S. Olivella and J. J. Stewart, J. Am. Chem. Soc., 1986, 108, 5771-5779.

2 F. Breher, Coord. Chem. Rev., 2007, 251, 1007-1043.

3 M. Abe, Chem. Rev., 2013, 113, 7011-7088.

4 E. Niecke, A. Fuchs, F. Baumeister, M. Nieger and W. W. Schoeller, Angew. Chem., 1995, 107, 640-642; Angew. Chem., Int. Ed., 1995, 34, 555-557.

5 D. Scheschkewitz, H. Amii, H. Gornitzka, W. W. Schoeller, D. Bourissou and G. Bertrand, Science, 2002, 295, 1880-1882. 6 H. Sugiyama, S. Ito and M. Yoshifuji, Angew. Chem., 2003, 115, 3932-3934; Angew. Chem., Int. Ed., 2003, 42, 3802-3804.

7 C. Cui, M. Brynda, M. M. Olmstead and P. P. Power, J. Am. Chem. Soc., 2004, 124, 6510-6511.

8 K. Takeuchi, M. Ichinohe and A. Sekiguchi, J. Am. Chem. Soc., 2011, 133, 12478-12481.

9 C. Cui, M. Brynda, M. M. Olmstead and P. P. Power, J. Am. Chem. Soc., 2004, 126, 6510-6511.

10 P. Henke, T. Pankewitz, W. Klopper, F. Breher and H. Schnöckel, Angew. Chem., 2009, 121, 8285-8290; Angew. Chem., Int. Ed., 2009, 48, 8141-8145.

11 H. Cox, P. B. Hitchcock, M. F. Lappert and L. J.-M. Pierssens, Angew. Chem., 2004, 116, 4600-4604; Angew. Chem., Int. Ed., 2004, 43, 4500-4504.

12 S.-H. Zhang, H.-W. Xi, K. H. Lim, Q. Meng, M.-B. Huang and C.-W. So, Chem.-Eur. J., 2012, 18, 4258-4263.

13 S. L. Buchwalter and G. L. Closs, J. Am. Chem. Soc., 1975, 97, 3857-3858.

14 F. Kita, W. Nau, W. Adam and J. Wirz, J. Am. Chem. Soc., 1995, 8670-8671.

15 W. R. Roth, F. Bauer and R. Breuckmann, Chem. Ber., 1991, 124, 2041-2046.

16 W. Adam, H. García, M. Diefenbach, V. Martí, M. Olivucci and E. Palomares, J. Am. Chem. Soc., 2002, 124, 12192-12199.

17 M. Abe, C. Ishihara, S. Kawanami and A. Masuyama, J. Am. Chem. Soc., 2005, 127, 10-11.

18 A. Maeda, T. Oshita, M. Abe and T. A. Ishibashi, J. Phys. Chem. B, 2014, 118, 3991-3997.

19 W. Adam, M. Diefenbach and V. Martí, Eur. J. Org. Chem., 2003, 592-596.

20 T. H. Peterson and B. K. Carpenter, J. Am. Chem. Soc., 1993, 115, 5466-5478.

21 M. Abe, S. Kawanami, C. Ishihara and M. Nojima, J. Org. Chem., 2004, 69, 5622-5626.
22 W. Adam, K. Goller, T. Kammel and K. Peters, J. Org. Chem., 1995, 60, 308-316.

23 W. Adam, H. Platsch, J. Sendelbach and J. Wirz, J. Org. Chem., 1993, 58, 1477-1482.

24 M. Abe, W. Adam and W. M. Nau, J. Am. Chem. Soc., 1998, 120, 11304-11310.

25 M. Abe, W. Adam, W. T. Borden, M. Hattori, D. A. Hrovat, M. Nojima, K. Nozaki and J. Wirz, J. Am. Chem. Soc., 2004, 126, 574-582.

26 J. Ye, Y. Fujiwara and M. Abe, Beilstein J. Org. Chem., 2013, 9, 925-933.

27 S. Ito, M. Kikuchi, J. Miura, N. Morita and M. Yoshifuji, J. Phys. Org. Chem., 2012, 25, 733-737.

$28 \mathrm{~S}$. Ito, M. Kikuchi, M. Yoshifuji, A. J. Arduengo, T. A. Konovalova and L. D. Kispert, Angew. Chem., 2006, 118, 4447-4451; Angew. Chem., Int. Ed., 2006, 45, 4341-4345.

29 H. Sugiyama, S. Ito and M. Yoshifuji, Chem.-Eur. J., 2004, 10, 2700-2706.

30 S. Ito, M. Kikuchi, H. Sugiyama and M. Yoshifuji, J. Organomet. Chem., 2007, 692, 2761-2767.

31 X. Wang, Y. Peng, M. M. Olmstead, J. C. Fettinger and P. P. Power, J. Am. Chem. Soc., 2009, 131, 14164-14165.

32 A. Hinz, A. Schulz and A. Villinger, Angew. Chem., 2014, 127, 678-682; Angew. Chem., Int. Ed., 2014, 54, 668-672.

33 A. Hinz, A. Schulz, A. Villinger and J.-M. Wolter, J. Am. Chem. Soc., 2015, 137, 3975-3980.

34 A. Hinz, J. Rothe, A. Schulz and A. Villinger, Dalton Trans., 2016, 2, 2016.

35 H. Amii, L. Vranicar, H. Gornitzka, D. Bourissou and G. Bertrand, J. Am. Chem. Soc., 2004, 126, 1344-1345.

36 G. Fuks, N. Saffon, L. Maron, G. Bertrand and D. Bourissou, J. Am. Chem. Soc., 2009, 131, 13681-13689.

37 M. Sebastian, A. J. Hoskin, M. Nieger, L. Nyulászi and E. Niecke, Angew. Chem., 2005, 117, 1429-1432; Angew. Chem., Int. Ed., 2005, 44, 1405-1408.

38 M. Sebastian, M. Nieger, D. Szieberth, L. Nyulászi and E. Niecke, Angew. Chem., 2004, 116, 647-651; Angew. Chem., Int. Ed., 2004, 43, 637-641.

39 A. Hinz, R. Kuzora, U. Rosenthal, A. Schulz and A. Villinger, Chem.-Eur. J., 2014, 20, 14659-14673.

40 A. Hinz, A. Schulz and A. Villinger, Chem.-Eur. J., 2014, 20, 3913-3916.

41 G. H. Spikes, J. C. Fettinger and P. P. Power, J. Am. Chem. Soc., 2005, 127, 12232-12233.

42 C. Cui, M. M. Olmstead, J. C. Fettinger, G. H. Spikes and P. P. Power, J. Am. Chem. Soc., 2005, 127, 17530-17541.

43 X. Wang, Y. Peng, Z. Zhu, J. C. Fettinger, P. P. Power, J. Guo and S. Nagase, Angew. Chem., 2010, 122, 4697-4701; Angew. Chem., Int. Ed., 2010, 49, 4593-4597.

44 A. Hinz, A. Schulz and A. Villinger, Angew. Chem., 2015, 127, 2815-2819; Angew. Chem., Int. Ed., 2015, 54, 2776-2779.

45 A. Hinz, A. Schulz and A. Villinger, J. Am. Chem. Soc., 2015, 137, 9953-9962.

46 S. Demeshko, C. Godemann, R. Kuzora, A. Schulz and A. Villinger, Angew. Chem., 2013, 125, 2159-2162; Angew. Chem., Int. Ed., 2013, 52, 2105-2108. 
47 J. A. W. Sklorz, S. Hoof, M. G. Sommer, F. Weißer, M. Weber, J. Wiecko, B. Sarkar and C. Müller, Organometallics, 2014, 33, 511-516.

48 J. A. W. Sklorz, S. Hoof, N. Rades, N. de Rycke, L. Könczöl, D. Szieberth, M. Weber, J. Wiecko, L. Nyulászi, M. Hissler and C. Müller, Chem.-Eur. J., 2015, 21, 11096-11109.

49 S. L. Choong, C. Jones and A. Stasch, Dalton Trans., 2010, 39, 5774-5776.

50 S. L. Choong, A. Nafady, A. Stasch, A. M. Bond and C. Jones, Dalton Trans., 2013, 42, 7775-7780.

51 M. J. Frisch, G. W. Trucks, H. B. Schlegel, G. E. Scuseria, M. A. Robb, J. R. Cheeseman, G. Scalmani, V. Barone, B. Mennucci, G. A. Petersson, H. Nakatsuji, M. Caricato, X. Li, H. P. Hratchian, A. F. Izmaylov, J. Bloino, G. Zheng, J. L. Sonnenberg, M. Hada, M. Ehara, K. Toyota, R. Fukuda, J. Hasegawa, M. Ishida, T. Nakajima, Y. Honda, O. Kitao, H. Nakai, T. Vreven, J. A. Montgomery, J. E. Peralta, F. Ogliaro, M. Bearpark, J. J. Heyd, E. Brothers, K. N. Kudin, V. N. Staroverov, R. Kobayashi, J. Normand, K. Raghavachari, A. Rendell, J. C. Burant, S. S. Iyengar, J. Tomasi, M. Cossi, N. Rega, J. M. Millam, M. Klene, J. E. Knox, J. B. Cross, V. Bakken, C. Adamo, J. Jaramillo, R. Gomperts, R. E. Stratmann, O. Yazyev, A. J. Austin, R. Cammi, C. Pomelli, J. W. Ochterski, R. L. Martin, K. Morokuma, V. G. Zakrzewski, G. A. Voth,
P. Salvador, J. J. Dannenberg, S. Dapprich, A. D. Daniels, Ö. Farkas, J. B. Foresman, J. V. Ortiz, J. Cioslowski and D. J. Fox, Gaussian 09, Revision C.01, Gaussian, Inc., Wallingford CT, 2009.

52 All computations were carried out at the PBE1PBE or $\operatorname{CASSCF}(6,6)$ level of theory. For $\mathrm{Sb}$, a relativistic pseudopotential was used (ECP46MDF 4 46), while for all other atoms 6-31G(d,p) was employed.

53 A. Schulz and A. Villinger, Angew. Chem., 2008, 120, 614-617; Angew. Chem., Int. Ed., 2008, 47, 603-606.

54 P. Pyykkö and M. Atsumi, Chem.-Eur. J., 2009, 15, 1277012779.

55 M. Kuprat, A. Schulz and A. Villinger, Angew. Chem., 2013, 125, 7266-7270; Angew. Chem., Int. Ed., 2013, 52, 7126-7130.

56 S. Herler, P. Mayer, J. Günne, A. Schulz, A. Villinger, J. J. Weigand and J. Schmedt auf der Günne, Angew. Chem., 2005, 117, 7968-7971; Angew. Chem., Int. Ed., 2005, 44, 7790-7793.

57 P. von R. Schleyer, C. Maerker, A. Dransfeld, H. Jiao and N. J. R. van E. Hommes, J. Am. Chem. Soc., 1996, 118, 6317-6318.

58 E. Miliordos, K. Ruedenberg and S. S. Xantheas, Angew. Chem., 2013, 125, 5848-5851; Angew. Chem., Int. Ed., 2013, 52, 5736-5739. 